\title{
170 UNESC EM DANÇA: FORMAÇÃO E GESTÃO DE PROJETOS CULTURAIS
}

Maxwell Sandeer Flor ${ }^{1}$, Amalhene Baesso Reddig ${ }^{2}$

\section{INTRODUÇÃo}

A Universidade do Extremo Sul Catarinense - Unesc, por meio das suas Políticas de Cultura (Resolução n 04/2011 - CÂMARA/PROPEX) incentiva atividades institucionais culturais, tais como a realização de Festivais (dança, música e teatro), e, ainda, com o intuito de aproximar a comunidade regional em torno da linguagem artístico-cultural da dança, propõe desde 1999 o projeto Unesc em Dança. O referido projeto trata-se de um festival de dança que desde a sua primeira edição é aberto a todos os gêneros de dança e gratuito ao público espectador. Em 2016, a Unesc realizou o projeto cultural $17^{\circ}$ Unesc em Dança, no Teatro Municipal Elias Angeloni - Criciúma/SC, registrando a participação de aproximadamente 5.000 pessoas.

Com o objetivo de "avaliar o grau de satisfação com relação ao evento", o Setor de Avaliação Institucional (SEAI) da Unesc elaborou, em parceria com a Comissão Organizadora responsável pela execução do $17^{\circ}$ Unesc em Dança (Portaria $n^{\circ}$ 09/2016/PROPEX) um questionário online, contendo questões fechadas, visando coletar dados a fim de avaliar o festival de forma integrada. Aqui apresentamos os dados coletados e avaliados sob a ótica do guia de gerenciamento de projetos (PMBOK®). Na pesquisa foram contemplados 21 indicadores, subdivididos em 03 (três) eixos (Infraestrutura, Programação e Organização). A partir da análise dos resultados obtidos, os mesmo foram usados nesse artigo, como subsídios para elaboração de estratégias para os aspectos que precisam ser melhorados, bem como fortalecer as potencialidades identificadas na avaliação.

\section{FORMAÇÃO E GESTÃo CULTURAL}

Segundo Xavier (2009), o gerenciamento de projetos é o ato ou ação de gerir, executar a gerência. No mercado o cliente analisa o sucesso do produto/serviço, e tem levado as

\footnotetext{
${ }^{1}$ Acadêmico de Pós-Graduação e Produtor Cultural da Unesc.

${ }^{2}$ Docente e Coordenadora do Setor Arte e Cultura da Unesc.
} 
organizações a viver em permanente estado de mudança, seja em inovações tecnológicas ou acrescentando melhorias no serviço atual. Inclusive no que se refere a projetos culturais o processo de formação também implica na gestão de pessoas, análise de resultados e difusão de informações.

O papel do gestor cultural passa por:

[...] programar normas, planos e projetos, estabelecer estruturas, alocar recursos humanos, financeiros, físicos e tecnológicos e, principalmente, empenhar criatividade e capacidade de inovação para atingir esses objetivos da melhor forma possível (RIBEIRO, 2009, p. 7).

"Um gestor cultural não nasce gestor, diferentemente dos talentos inatos, geralmente identificados como o artista" (LEITÃO, 2014, p. 33). Quando finalizamos um ciclo, já estamos pensando/planejando outra etapa do projeto cultural. Gerenciar estratégia de ações e direcionar atribuições para os colaboradores do projeto são habilidades interpessoais do gerente de projeto (GP).

A combinação equilibrada de habilidades interpessoais, tais como liderança, comunicação, influência, tomada de decisões, consciência política e cultural, negociação, gerenciamento de conflitos e coaching, são prerrogativas para a boa gestão de projetos culturais (XAVIER, 2009).

\section{DEFINIÇÃO E RESULTADO DA PESQUISA}

Para definir amostra da pesquisa, considerou-se os participantes do $17^{\circ}$ Unesc em Dança/2016, que deixaram seus e-mails com a Comissão Organizadora, afim de, posteriormente, participar na avaliação. Foram recebidos 264 e-mails de indivíduos interessados. Segundo PMI (2003) a parte interessada é um indivíduo, grupo ou organização que pode afetar, ser afetada ou sentir-se afetada por uma decisão, atividade ou resultado de um projeto. Os interessados que responderam ao questionário foram: dançarinos, coreógrafos e plateia presente no festival. Esses sujeitos que responderam a pesquisa pensam de diferentes formas, acessam a cultura e a arte da dança a partir dos seus referenciais e, naturalmente, avaliaram o festival de formas distintas e contribuíram com o processo de avaliação do projeto.

As partes interessadas podem exercer influência sobre o festival ao atribuir retornos de insatisfação, por exemplo: durante a execução do evento o coreógrafo pode entregar a música errada, a iluminação pode apresentar problemas técnicos, o avaliador pode chegar atrasado, entre outras situações que podem prejudicar a execução do evento. $\mathrm{O}$ conjunto de resultados 
que atenda os objetivos do projeto cultural deve estar alinhados com as necessidades do público de interesse.

O processo do projeto cultural com o guia de gerenciamento de projetos (PMBOK®) viabiliza a gerência consistente de todo o ciclo de vida do projeto: iniciação, planejamento, execução e encerramento. Assim, maximizando o valor dos resultados do projeto, alinhando os indicadores com as estratégias das ações.

No que tange ao resultado geral da pesquisa do $17^{\circ}$ Unesc em Dança, foi considerado positivo, tendo em vista a predominância de conceito médio com valor superior a 4 , numa escala de 1 a 5, como pode ser visto no quadro abaixo.

Quadro 1. Infraestrutura, Programação e Organização.

\begin{tabular}{|c|c|c|c|c|c|}
\hline Infraestrutura: & MP & Programação: & MP & Organização: & MP \\
\hline 1 - Recepção & 4,40 & 10 - Oficinas oferecidas & 4,36 & 16 - Declarações & 4,38 \\
\hline 2 - Atendimento & 4,42 & 11 - Mesa redonda & 4,14 & 17 - Site & 4,07 \\
\hline 3 - Fotografia & 4,21 & $\begin{array}{l}12 \text { - Exposição } \\
\text { fotográfica }\end{array}$ & 4,20 & 18 - Horário & 4,08 \\
\hline 4 - Filmagem & 4,20 & 13 - Pôster & 4,23 & 19 - Local & 4,65 \\
\hline 5 - Som & 4,46 & 14 - Coreografias & 4,33 & 20 - Divulgação & 3,89 \\
\hline 6 - Palco & 4,61 & 15 - Menção Honrosa & 4,07 & 21 - Inscrições & 3,88 \\
\hline 7 - Iluminação & 4,55 & & & & \\
\hline 8 - Lanches & 3,60 & & & & \\
\hline 9 - Estacionamento & 4,02 & & & & \\
\hline & 4,31 & & 4,22 & & 4,16 \\
\hline
\end{tabular}

Fonte: SEAI, 2016.

Ressalta-se que a Média Ponderada (MP) entre 3,00 a 3,99 para os indicadores de números 8, 20 e 21, nos eixos Infraestrutura e Organização, não são percebidas como um valor negativo, e sim como indicadores relevantes para definir ações futuras no primeiro ciclo do próximo projeto. Isso deve ser considerado na definição dos fornecedores e no planejamento ampliado de comunicação/marketing. 


\section{CONSIDERAÇÕES FINAIS}

Considerando os resultados da pesquisa do $17^{\circ}$ Festival Unesc em Dança, percebemos que os setores envolvidos estão acumulando experiências com gerenciamento de projetos culturais, onde não fica limitado ao cumprimento da síntese/objeto. A reflexão do processo e análise da pesquisa feita pelo SEAI facilitará para construção de novas estratégias de ações, visando o fortalecimento de todos os indicadores. Os resultados ganharam a devida visibilidade, respeitando os princípios estabelecidos pela Política de Avaliação Institucional da UNESC $^{3}$, que está em consonância com o SINAES, de modo que a comunidade acadêmica possa conhecer e usufruir desses resultados.

A avaliação do $17^{\circ}$ Unesc em Dança, com o guia de gerenciamento de projetos (PMBOK®), possibilitou mostrar direções para planejar situações de risco, mesmo que estes apresentam nível baixo.

Nesse contexto, o compartilhamento destas informações para todos os setores que envolvem o projeto despertará para o desafio gerencial de ações integrativas. No processo educativo de pesquisa, ensino e extensão, poderá agregar com mais eficiência acadêmicos, professores, gestores, colaboradores, fornecedores, plateia da comunidade, grupos de dança, financiadores/patrocinadores, bem como outras "partes interessadas" que se envolvem direta ou indiretamente no projeto cultural.

\section{REFERÊNCIAS}

LEITÃO, C. S. Cultura em movimento: memórias e reflexões sobre políticas públicas e práticas de gestão. Fortaleza: Armazém da Cultura, 2014.

PMI. Um guia do conhecimento em gerenciamento de projetos. Guia PMBOK® Project Management Institute, 2013.

POLÍTICAS DE CULTURA DA UNESC, Resolução n ${ }^{\circ}$ 04/2011 - CÂMARA/PROPEX. Criciúma, 2011. 9 páginas.

RIBEIRO, L. F. Plural: Atuação Dinâmica e Transversal do Gestor Cultural. Bahia, 2010. Disponível em: <http://www.cult.ufba.br/wordpress/24592.pdf > Acesso em: 06 mar. 2016.

SETOR DE AVALIAÇÃO INSTITUCIONAL (SEAI) UNESC. Avaliação do $\mathbf{1 7}^{\mathbf{0}}$ Unesc em $^{-}$ Dança - Festival de Dança. Criciúma, 2016. 26 páginas.

XAVIER, C. M. S. Gerenciamento de Projetos: como definir e controlar o escopo do projeto. São Paulo: Saraiva, 2015.

\footnotetext{
${ }^{3}$ Resolução no 02/2015/CONSU. Aprova a Política para Avaliação Institucional da UNESC. Disponível em: <http://www.unesc.net/portal/resources/official_documents/11355.pdf?1429012894>. Acesso em: 26 set. 2016.
} 